This item was submitted to Loughborough's Research Repository by the author.

Items in Figshare are protected by copyright, with all rights reserved, unless otherwise indicated.

\title{
Evaluating the impacts of community renewable energy initiatives
}

PLEASE CITE THE PUBLISHED VERSION

PUBLISHER

(c) International Solar Energy Society

VERSION

AM (Accepted Manuscript)

LICENCE

CC BY-NC-ND 4.0

REPOSITORY RECORD

Leicester, Philip A., Chris I. Goodier, and Paul Rowley. 2019. "Evaluating the Impacts of Community Renewable Energy Initiatives”. figshare. https://hdl.handle.net/2134/9185. 
This item was submitted to Loughborough's Institutional Repository (https://dspace.lboro.ac.uk/) by the author and is made available under the following Creative Commons Licence conditions.

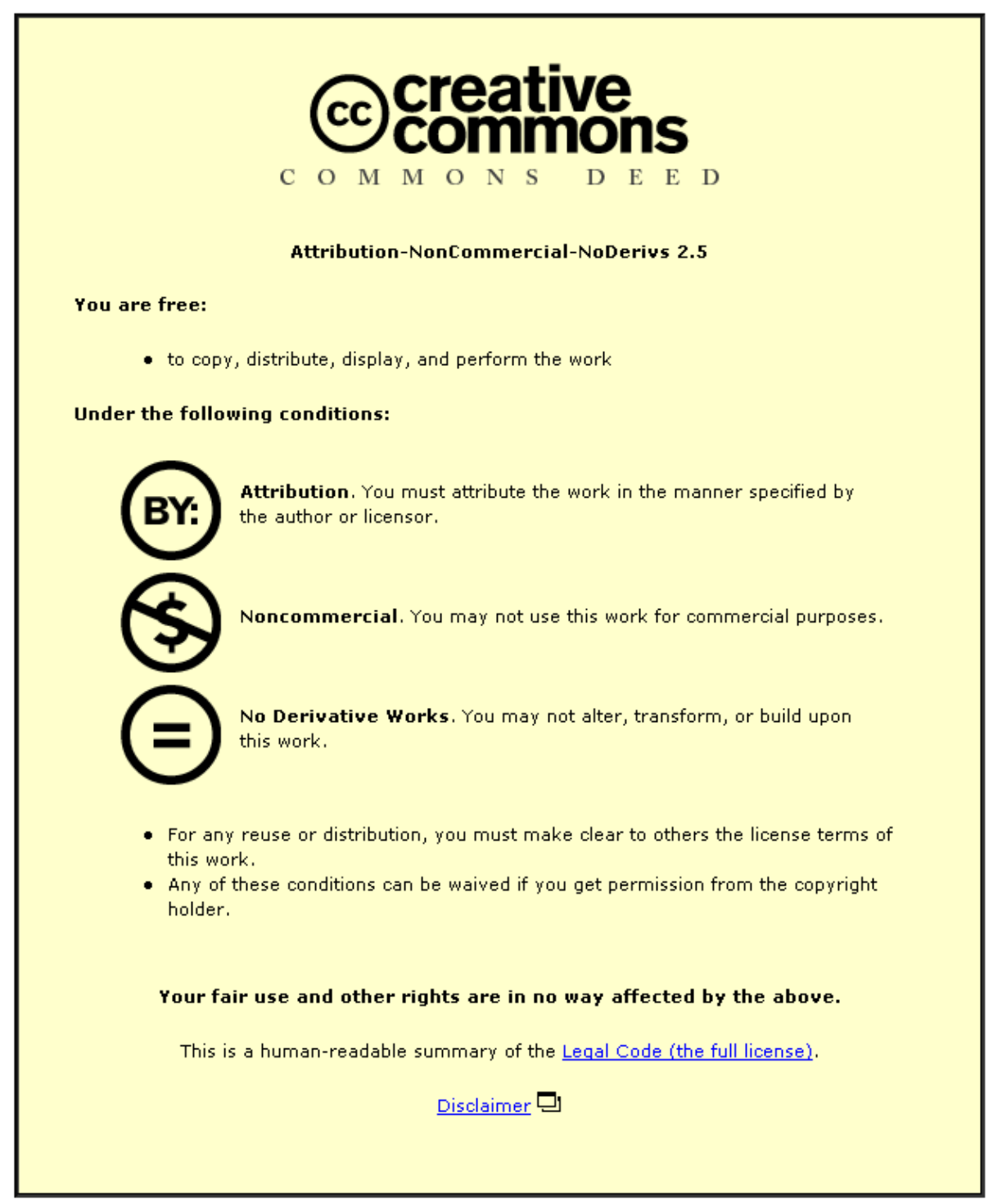

For the full text of this licence, please go to: http://creativecommons.org/licenses/by-nc-nd/2.5/ 


\title{
EVALUATING THE IMPACTS OF COMMUNITY RENEWABLE ENERGY INITIATIVES

\author{
Philip Leicester $^{1,2 凶}$, Chris Goodier $^{1}$ and Paul Rowley ${ }^{2}$ \\ ${ }^{1}$ School of Civil and Building Engineering, Loughborough University, United Kingdom \\ ${ }^{2}$ CREST, School of Electronic, Electrical and Systems Engineering, Loughborough University, United Kingdom
}

\begin{abstract}
1. Abstract
The UK is encouraging the adoption of distributed renewable energy technologies (RETs) in order to achieve carbon reduction targets and deliver on other energy policy objectives such as energy security. Latterly, through the adoption of a Feed-in Tariff (FiT) mechanism, RETs are now diffusing rapidly into local communities. There is therefore an urgent need to understand the rate and patterns of adoption of these technologies, and evaluate their impacts in specific community contexts.
\end{abstract}

A model for this diffusion of FiT-supported RETs into communities is presented together with a framework for measuring the potential impacts of community energy initiatives over a broad range of recent energy policy indicators.

The national register of FiT installations has been analysed alongside small-area socio-economic data such as indices of deprivation in order to explore variations in technology diffusion based upon type of RET, community affluence, built environment density, and geographical location. Particular pathways for the diffusion of RETs in UK communities have been discerned and localities identified and a concurrence with emerging literature on community innovations is discussed.

It is shown that photovoltaic technologies (PV) are penetrating more affluent communities in a highly dispersed and isolated nature, but some more specific community activity is also evident targeted at more deprived communities.

\section{Introduction}

Energy policy in the UK has evolved as market liberalisation which had its roots in the deregulatory utility Acts of the 1980s (Helm, 2002). Numerous Acts of Parliament and Government White Papers have, since this time, featured five major policy objectives: carbon emission reduction, economic competitiveness, energy conservation, social equity and energy security.

Carbon emission reduction has increasingly moved centre stage during this period, culminating in the Climate Change Act 2008, which sets a target of $80 \%$ reduction in carbon emissions by 2050 (UK, 2008). A low carbon economy with a significant renewables component is now firmly on the UK Government's agenda (Department of Energy and Climate Change, 2011a). The UK has a target of 15\% of all energy from renewable resources by 2020 (EU, 2009) from a 2010 baseline of 3.3\% (Department of Energy and Climate Change, 2011b). In order to attain these targets, the UK Government's response in a deregulated energy market has been to introduce a succession of market instruments in order to try and correct market failures and to help renewables to break through into an energy regime characterised by historical 'lock-in' to fossil fuels (Unruh, 2002). The main instrument, introduced in 2002, was the Renewables Obligation scheme which introduced tradable Renewable Obligation Certificates (ROC) (Mitchell and Connor, 2004). This had success in driving investment in large-scale renewables, but failed to enable smaller distributed energy generation technologies to make a breakthrough in the UK market, despite a number of capital grant programmes (Element Energy Limited, 2008). Following less than favourable comparisons between the ROC scheme and Feed-in Tariff mechanisms adopted elsewhere in Europe (Mitchell et al., 2006; Mendonça, 2007), the UK introduced its own FiT scheme in April 2010, aimed at reviving the stalled implementation of small scale (up to $5 \mathrm{MW}$ ) distributed renewables supported by an industry-government strategy to facilitate and encourage adoption by consumers (Department of Energy and Climate Change, 2011c). 
As well as contributing to carbon emission reduction, the burgeoning UK renewables sector has the potential to help deliver on the other policy objectives cited above. Experience in other countries indicates that economic benefits may be realised through industrial development and employment opportunities (Lipp, 2007). Citizens, encouraged by participation in energy generation, may also develop positive attitudes towards carbon emission reduction and individual and community behaviour towards energy conservation (Department of Energy and Climate Change, 2010). This has been described as the development of an energy citizenship where consumers have a greater understanding of energy usage through a direct relationship with its generation (Musall and Kuik, 2011).

A distributed energy system can have a major impact on social equity. Community projects are strongly encouraged to distribute benefits to local communities so as not to create resentment toward local RETs (Walker and Devine-Wright, 2008). At a domestic scale, RETs are expected to bring down energy costs and have a potential positive impact on energy (fuel) poverty (Walker, 2008). A household which spends, or would need to spend, more than $10 \%$ of its income to maintain adequate comfort - deemed to be $21^{\circ} \mathrm{C}$ in living quarters and $18^{\circ} \mathrm{C}$ elsewhere - is said to be in fuel poverty (Boardman, 2010). It is a combined function of the cost of fuel, income, and fuel consumption, the latter determined by lifestyle and building energy performance. Low income households in poor housing are particularly vulnerable and the impact is exacerbated by resultant ill-health and excess winter deaths of which there were an estimated 35,000 in 2008/9 (Marmot Review Team, 2011). A statutory legal requirement to eradicate the problem by 2010 for the most vulnerable households, and for all affected households by 2016, has been in place since 2001. Despite this, the incidence of fuel poverty had risen to 4 million households by 2009 (Department of Energy and Climate Change, 2011d), due largely to rising fuel prices. The problem has been termed 'a peculiarly British public health scandal and an affront to human rights' (Press, 2003, p. 5 cited in Walker, 2008).

\section{FiTs - a case study}

This paper examines the FiTs in England as a national case study to explore the potential of distributed renewable energy technologies (RETs) to have an impact on the UK energy policy objectives discussed above. Specific objectives of this work include:

- To develop and quantify a model for the diffusion of distributed RETs.

- To propose a framework, which can be used alongside this model, for the development of a methodology for the evaluation of the impacts of RETS on policy objectives following adoption by domestic and community actors.

- To derive lessons going forward from selected aspects of this framework in particular to highlight insights into activities to target RETs to address equity issues such as fuel poverty.

\section{Model for the Diffusion of Renewable Energy Technology}

Figure 1 provides a model showing the relationship between the three main actors involved in the diffusion of RETs. Government is responsible for the market instruments, in this case the FiTs scheme, to help consumers overcome the financial barriers to the adoption of RETs. It also sets the regulatory framework which establishes and governs the industry.

The industry actor can be regarded as a sectoral system of innovation (Malerba, 2004). This involves a range of stakeholders such as manufacturers, suppliers, marketers, installers and training organisations for example. The industry led Microgeneration strategy, and the process to develop it, is an attempt to establish a sectoral system of innovation for microgeneration designed to overcome non-financial barriers to and maintain consumer confidence adoption (Department of Energy and Climate Change, 2011c).

Consumers who adopt a RET are shown on the FiTs register as one of four types: community, domestic, commercial and industrial. In this work on community renewable energy, the focus is on domestic and community adopters, so the model emphasises community and domestic consumers. A domestic consumer is an individual or household which is the sole beneficiary. A community consumer is a collective or civil 
society group such as local authority or $3^{\text {rd }}$ sector organisation whose activities benefit a wider community of stakeholders.

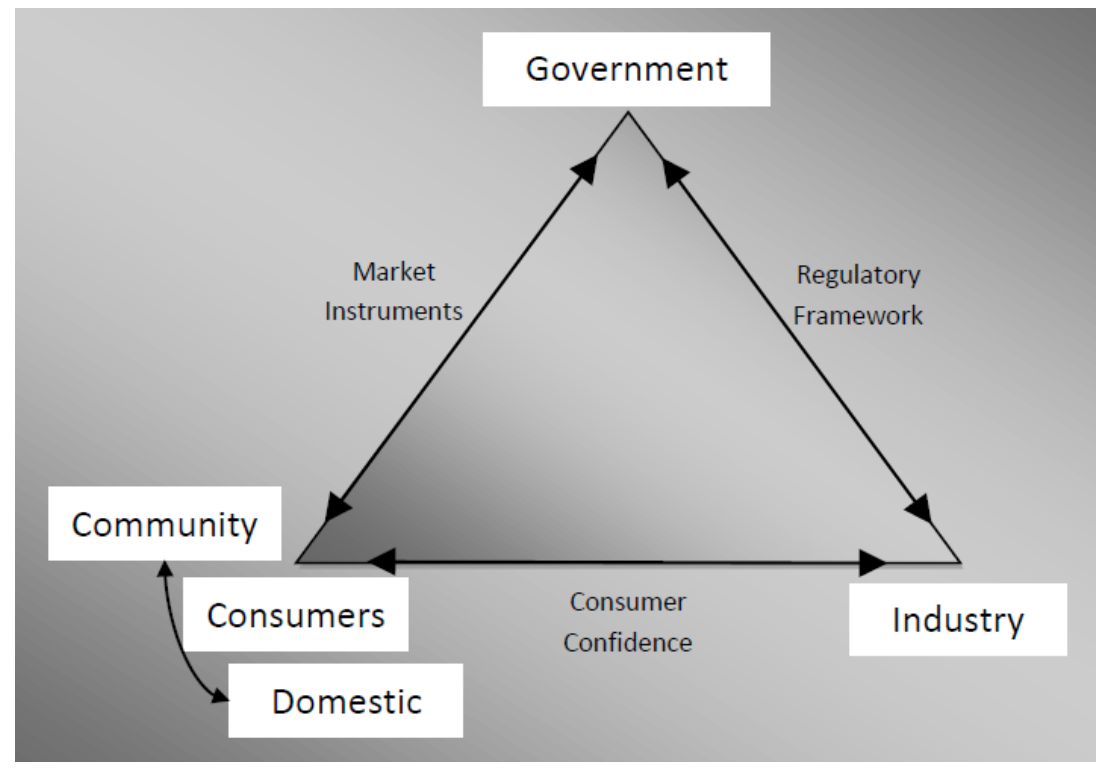

Figure 1 Actors involved in the diffusion of renewable energy technologies

It is important to note that on the FiTs register, the community category indicates that the registered consumer is a community building such as a village hall, synagogue or school, and is not necessarily indicative of a community initiative which has a number of households as beneficiaries. Thus domestic customers may have been influenced by or have participated in a community initiative, a fact which is not captured by the FiTs registration process. An objective of this work is to verify and quantify this model by discerning the two consumer types in the FiTs register and quantify the relative importance of the two consumer categories.

\section{Methodology}

In order to research the adoption of RETs by domestic and community consumers a composite dataset derived from the UK FiTs Register of installations, made available by the UK energy regulator, OFGEM, in May 2011, and other nationally available socio-economic datasets from the Office of National Statistics (ONS), downloaded in June 2011, has been constructed.

Each dataset contains a column for the Lower Layer Super Output Area (LSOA) codes. These are published by the Office of National Statistics and provide non-disclosive small area statistical data from the UK 2001 Census and other socio-economic statistical datasets. LSOAs are derived automatically using algorithms to yield as far as possible socially homogeneous areas constrained to be a minimum size of 1000 residents and 400 households (Martin et al., 2001). In the UK there are 34,378 LSOAs which have an average of 1500 residents. Every FiTs register entry has been allocated to the correct LSOA by OFGEM. This allows relational outer joins to be made between the datasets facilitating the direct linkage between FiT installations and the socio-economic data of its location.

The ONS datasets used provide the analysis with the index of multiple deprivation (IMD) and a rurality index. Because the latter data are not comparable across the UK nations, or are not readily available for Scotland and Wales, this study focuses on England. The use of the IMD dataset allows the accurate determination of the relative level of deprivation of each LSOA in which each RET is sited. The data has been analysed using standard spreadsheet pivot and other numerical functions e.g. for calculating deciles and frequency distributions. 


\section{Results}

The total number of installations supported by FiTs in England by May 2011 was over 32,000, distributed over four main supported technologies and consumer types of Community, Domestic, Commercial and Industrial (Table 1).

Under the FiTs photovoltaic technology (PV) is benefiting the most with over 31,000 installations and a generating capacity of $85.7 \mathrm{MW} .98 \%$ of PV installations are designated as domestic and $1 \%$ community. In terms of generating capacity, this is $95 \%$ domestic and $2 \%$ community.

Wind has a total of 782 installations with a generating capacity of $6.3 \mathrm{MW} .79 \%$ of these are designated domestic installations, with $6 \%$ community. $10 \%$ of the generating capacity of wind is due to community installations and $64 \%$ domestic, with the rest due to commercial and industrial installations.

Hydro has a generating capacity of $1.2 \mathrm{MW}$ from 1177 installations; of these $8 \%$ are community installations, $74 \%$ domestic and $18 \%$ commercial and industrial. In terms of generating capacity, $8 \%$ is due to community installations, $54 \%$ domestic and $38 \%$ commercial and industrial.

Anaerobic digestion (AD) has suffered a poor start with only 1 installation in England. The UK Government have acted in June 2011 to increase the tariff in order to incentivise the uptake of farm-scale AD by increasing the return on capital investment (Department of Energy and Climate Change, 2011e).

Table 1 Number of FiT installations by technology and consumer type, total generating capacity, and number installed under previous grant schemes.

\begin{tabular}{|c|c|c|c|c|c|c|c|}
\hline \multirow[t]{2}{*}{ Technology } & \multicolumn{5}{|c|}{ Number of FiT Installations } & \multirow{2}{*}{$\begin{array}{l}\text { Total } \\
\text { Capacity } \\
\text { (MW) }\end{array}$} & \multirow{2}{*}{$\begin{array}{l}\text { Grant } \\
\text { Schemes } \\
\text { (Number) }\end{array}$} \\
\hline & Community & Domestic & Commercial & Industrial & Total & & \\
\hline $\mathrm{AD}$ & & & 1 & & 1 & 1.1 & \\
\hline Hydro & 7 & 64 & 14 & 2 & 87 & 1.2 & 16 \\
\hline PV & 277 & 30791 & 244 & 31 & 31343 & 85.7 & 2511 \\
\hline Wind & 49 & 618 & 111 & 4 & 782 & 6.3 & 784 \\
\hline Total & 333 & 31583 & 370 & 37 & 32323 & 94.4 & 3311 \\
\hline
\end{tabular}

\section{Diffusion in to England}

The total number of installations of the key technologies delivered under earlier capital grant schemes is shown for comparison in Table 1 (Element Energy Limited, 2008). This suggests that the FiTs regime has, in one year, contributed to a 10-fold increase in the number of microgeneration installations compared to earlier capital grant schemes such as the Major PV demonstration programme, Clear Skies and the Low Carbon Building Programmes over the previous 10 years. This is commensurate with an order of a 100-fold increase in the rate of technology diffusion.

The profile of the accumulative increase in the generating capacity of microgeneration since 2005 is shown in Figure 2 is possibly characteristic of the beginning of the classic S-shaped temporal curve for the diffusion of innovations (Rogers, 1995). Rogers categorised adopters as innovators, early adopters, early majority, late majority and laggards. If current adopters are innovators, which Rogers assumes to be $2.5 \%$ of all potential adopters, then this yields about $1.5 \mathrm{M}$ potential adopters. Innovators and early adopters put more weight on personal motivations, whilst majority adopters are motivated by more social rather than individual aspirations. This has implications on the marketing of technologies if the Government's aim, over the lifetime of the FiTs regime to support over 750,000 small-scale RETs by 2020 is to be achieved (Department of Energy and Climate Change, 2010). This suggests an average annual installation rate of over 80,000 microgeneration units per year; just under half of this has been achieved in the first year. 


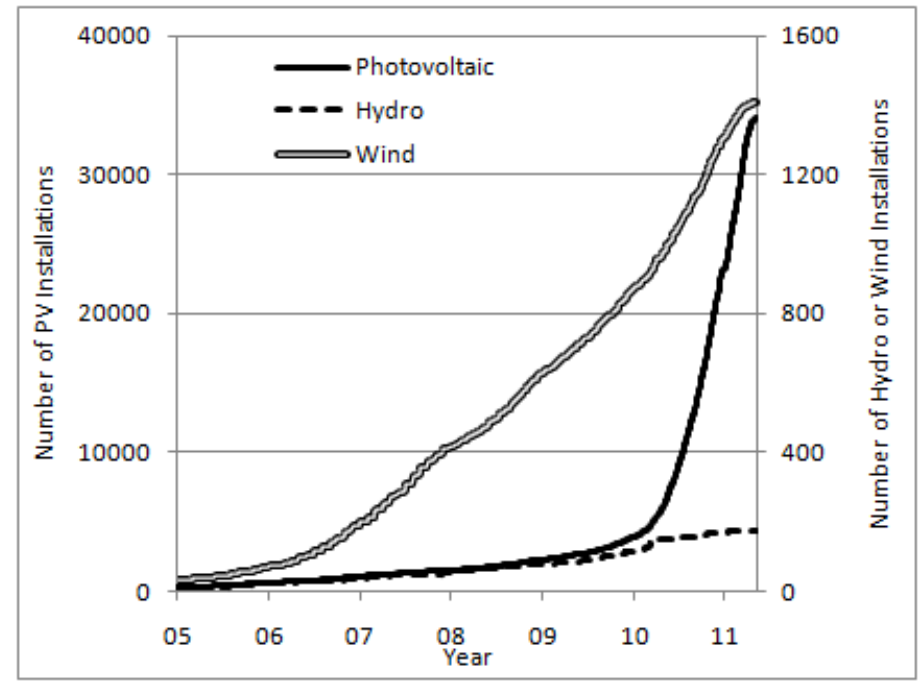

Figure 2 Accumulative increase in installations for Wind, Hydro and PV 2005-2011

\section{Diffusion into differing settlement densities}

The relative diffusion of technologies into urban and rural communities can be investigated using a rural/urban classification developed for the UK Government which allocates an LSOA to a number of rurality types (Bibby and Shepherd, 2004). For our exploratory purposes a simple three-way classification: Urban, 'Town and Fringe' and 'Village, Hamlet and Isolated Dwellings', was applied. Urban refers to LSOAs which are part of, or border, areas with a population of 10,000 or more.

In numerical terms, the apparent relative adoption of PV in urban communities is much higher compared to town and fringe, and village areas, but taking into account the number of potential adopter households - 80\% of the population lives in urban areas - the difference all but disappears (Figure 3). It can be concluded that the rate of adoption is insensitive to the degree of urbanisation.

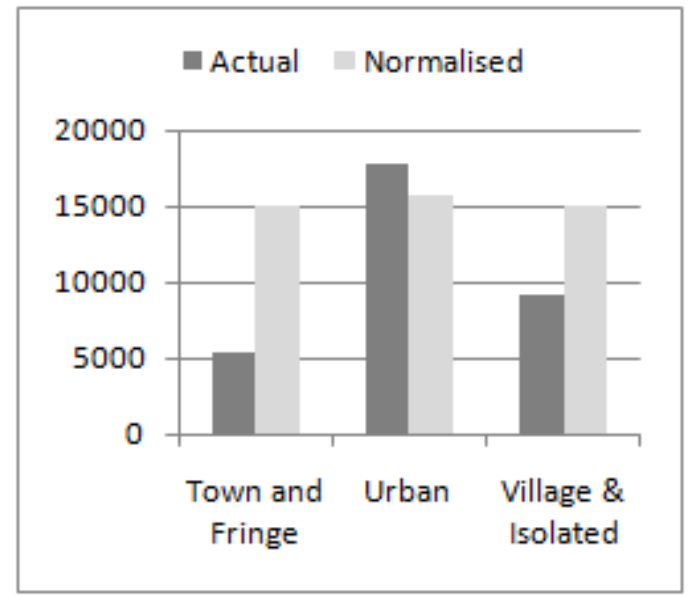

Figure 3 Number of PV installations in urban and rural areas; actual and normalised to $10 \mathrm{M}$ households.

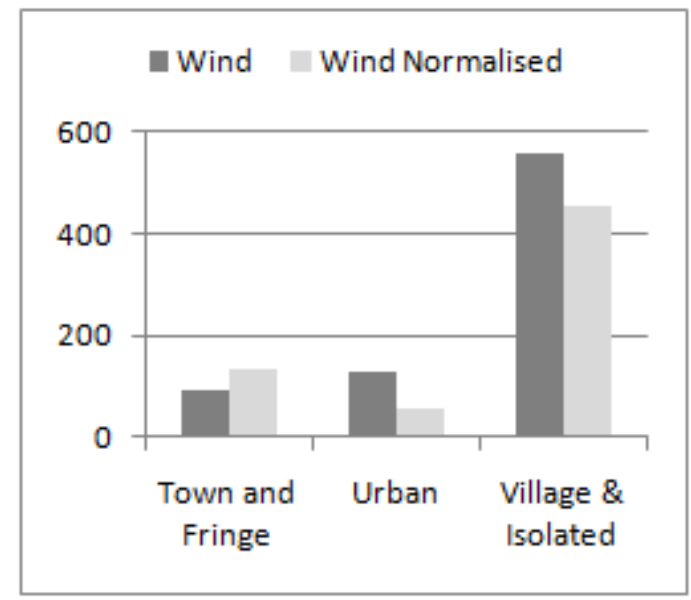

Figure 4 Wind installations in urban and rural areas; actual and normalised to $5 \mathrm{M}$ households.

The picture is quite different for wind (Figure 4), which shows an expected higher adoption rate in rural areas compared to higher housing density areas. Wind technology is more suited to low density settlements since wind speed and turbulence are adversely impacted by the built environment (Heath et al., 2007). Wind installations are also subject to planning regulations. Thus it is expected that Wind installation rates are sensitive to the degree of urbanisation. 
Significantly, 618 turbines are classified as domestic and only 49 as community. There is much scope for exploring to what extent turbines are facing local objections and the degree to which community benefits or ownership models are facilitating the rate of adoption of this technology and the extent and type of barriers still in place which is creating this differential. PV is more planning neutral, though anecdotally there are wide variations in the interpretation of planning guidance aimed to ease installation of unobtrusive technology. This suggests that there is not a significantly different agency in urban, compared to more rural, areas. Some large-scale urban initiatives, such as the Birmingham Energy Savers Programme, which aims to install solar PV systems on 10,000 social housing dwellings with FiTs being used to pay back the costs, are in development but do not yet show in the available data. This may shift the trend towards urban areas unless rural areas create similar schemes.

\section{Diffusion into Communities - Principal Local Authority Areas}

An analysis focussed on principal local authorities (PLAs), the UK's primary administrative unit of local government, yields a significant variation in the diffusion of microgeneration. Figure 5 shows the number of PLAs with the given ranges of RETs installed under the FiT scheme.

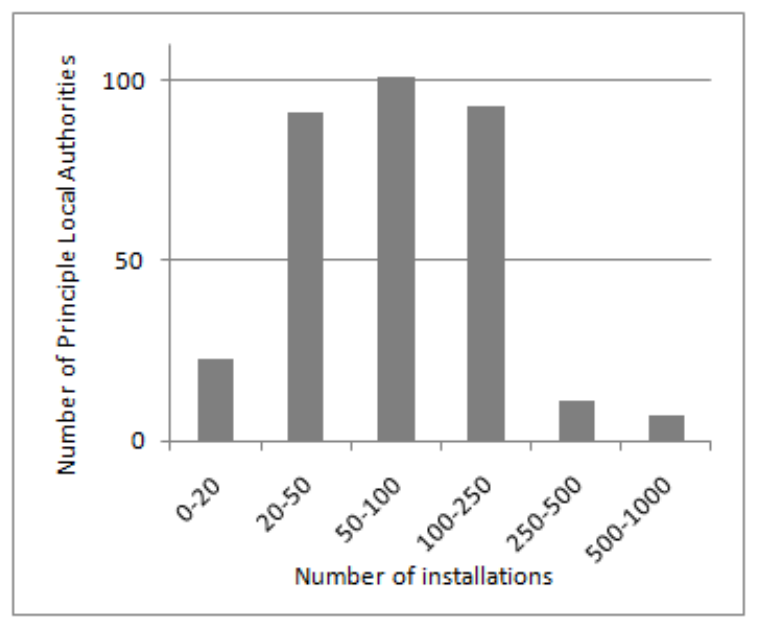

Figure 5 Number of Principle Local Authorities with the given range of installations under the FiTs

Only 18 PLAs exhibit diffusion rates above 250 units, and an inspection of the authorities featuring in the 500-1000 band reveals a regional Yorkshire cluster (Table 2). This analysis is pertinent with respect to theory on the diffusion of innovations and the role of socio-technical niches and the multi-layer perspective (Geels, 2002); this is discussed further below.

Table 2 English Authorities with the highest number of installations

\begin{tabular}{|c|c|c|c|}
\hline Local Authority & Population & Number of installations & Region \\
\hline Cornwall & 531100 & 887 & South West \\
\hline Wiltshire & 456100 & 590 & South West \\
\hline Sheffield & 547000 & 584 & Yorkshire \\
\hline Kirklees & 406800 & 547 & Yorkshire \\
\hline Barnsley & 226300 & 539 & Yorkshire \\
\hline Isle of Wight & 140200 & 527 & South East \\
\hline Doncaster & 290100 & 505 & Yorkshire \\
\hline
\end{tabular}

\section{Wealth Analysis}

PLAs differ significantly in terms of their relative prosperity, and within them they are socio-economically heterogeneous. The UK's Index of Multiple Deprivation (IMD) has been developed as a composite index of 
indices of deprivation and a value for each LSOA has been published by the Office for National Statistics. IMD is not an absolute indicator but can be used for comparative statistical studies. This enables small-area geographical analysis of the diffusion of microgeneration technology based on relative affluence or deprivation. A comparison of the rate of diffusion of PV and wind installations in LSOAs based on their IMD is shown in Figure 6.

This confirms that PV technology is penetrating less affluent LSOAs more slowly than affluent areas, indicative of a market-orientated financial mechanism, requiring a significant capital outlay or financial acumen, operating as the driver of diffusion. Wind, on the other hand, presents a different picture, with the apparent presence of greater barriers to adoption in both the most and least affluent areas.

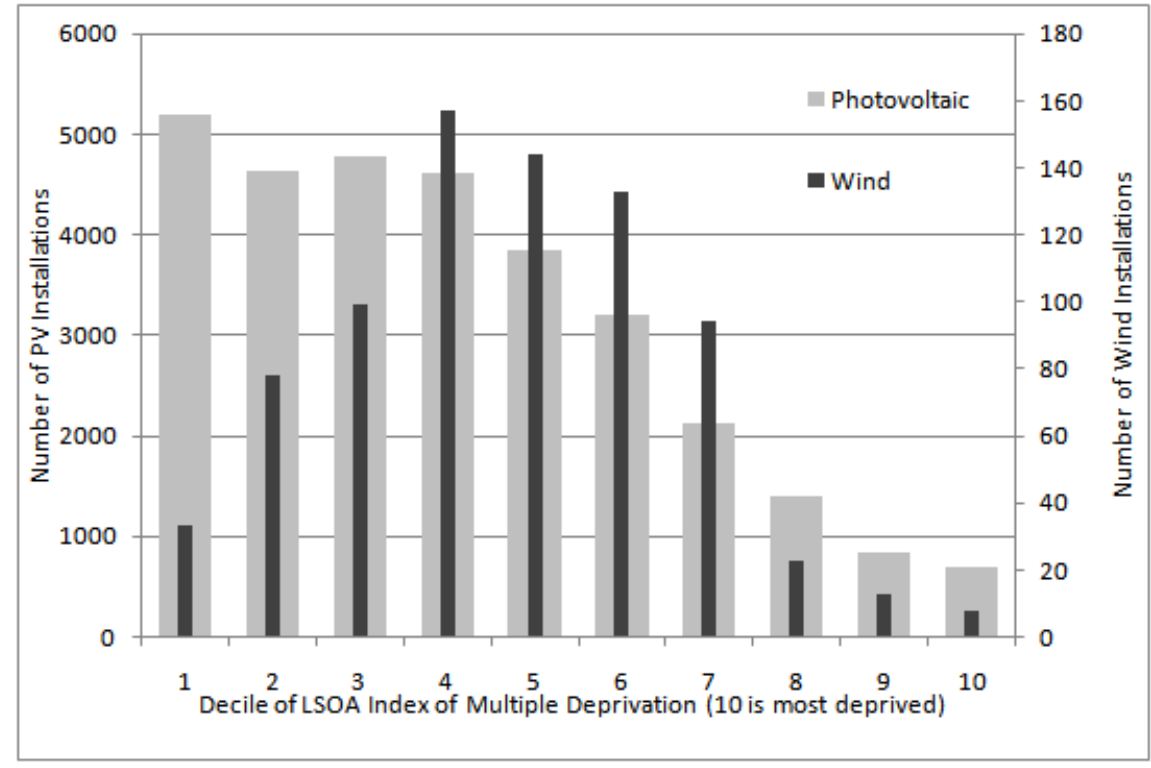

Figure 6 Number of Installations in each decile of IMD (1 is most affluent, 10 is most deprived)

Above (Table 2) it was shown that a number of PLAs exhibit a higher than typical number of FiT installations. Using the much smaller LSOAs, there is an opportunity to explore the evidence for more localised energy initiatives. Figure 7 shows all the number of English LSOAs with the given range of FiTs installations.

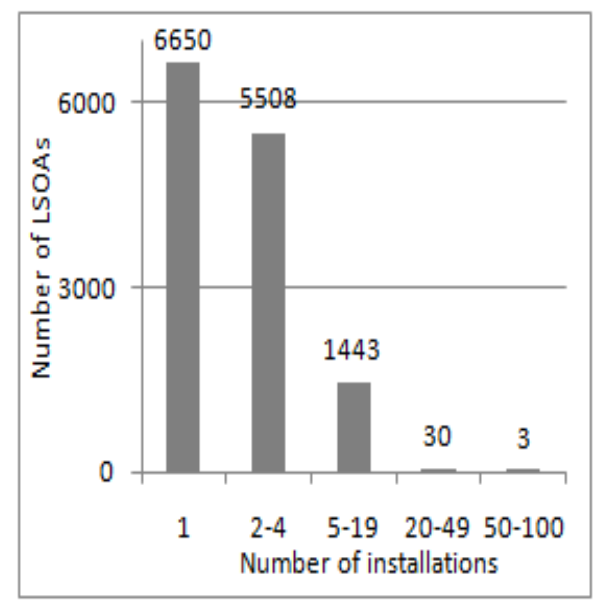

Figure 7 Number of LSOAs with the given range of installations 
This shows that the overwhelming majority of installations are in very small clusters of mainly one, or two to four, installations within a single LSOA. This suggests that diffusion is not yet proceeding to any great degree by a nudge, or peer-pressure, behavioural change dynamic between near neighbours, though it may be too early to observe this effect (Dobson, 2010). It reinforces the idea of evenly dispersed individualistic adopters but concentrated in more affluent localities. There is little sign of a significant deployment of microgeneration on a whole-street or neighbourhood scale except in, perhaps, the minority 33 LSOAs with 20 or more installations. The ten LSOAs with the highest number of FiT installations are shown in Table 3 alongside their respective local authorities. These stand out as areas of potential community energy initiatives which are operating under a different dynamic than those LSOAs containing just 1 or several installations. Of these, three are in the most deprived IMD deciles (Kirklees, Stoke-on-Trent and St Helens). This is noteworthy, in terms of identifying community initiatives which are targeting low income households.

Table 3 Location of LSOAs with high installation rates and high IMD

\begin{tabular}{|l|c|c|}
\hline LSOA PLA & $\begin{array}{c}\text { Number of FiTs } \\
\text { Installations }\end{array}$ & IMD Decile \\
\hline Kirklees & 87 & 10 \\
\hline Stoke-on-Trent & 57 & 10 \\
\hline Isle of Wight & 56 & 6 \\
\hline St. Helens & 49 & 10 \\
\hline Isle of Wight & 46 & 8 \\
\hline Welwyn Hatfield & 46 & 3 \\
\hline Sheffield & 45 & 7 \\
\hline Isle of Wight & 45 & 4 \\
\hline South Hams & 44 & 3 \\
\hline Stratford-on-Avon & 38 & 4 \\
\hline
\end{tabular}

\section{Discussion}

This analysis of the composite FiTs datasets shows clusters of domestic PV installations in specific PLAs and LSOAs. This suggests the possibility of an organised community initiative rather than individual domestic consumers responding to market signals, particularly those in the most deprived LSOAs. Figure 7 suggests that a very small fraction of PV systems result from geographically localised community activities. For example only $11 \%$ of FiTs installations are located in LSOAs - areas with a minimum of 400 dwellings with 10 or more other installations in the same LSOA. The remaining PV installations are highly dispersed domestic installations.

This reinforces and quantifies two actor types, domestic and community, but which do not necessarily correspond to the category in the FiTs register. The methodology outlined here enables their identification as follows:

- Domestic actors: able to overcome economic barriers, evidenced by highly dispersed activity in more affluent localities. This suggests a diffusion of innovation driven by the sectoral system of innovation influencing largely 'able to pay' actors exhibiting pro-environment citizenship behaviour or simply realising a good personal financial investment (Dobson, 2010).

- Community actors: evidenced by highly localised activity in, for example, Kirklees and Cornwall, discernable as higher than typical density PV installations in affluent and deprived communities, 49 wind projects identified as owned by 'community' stakeholders and some specific community PV projects. 
The situation is further complicated by domestic actors who may be influenced by not just the sectoral system of innovation, but additionally by community actors. These may not show up as geographic clusters but may also be widely dispersed. They may each be influenced by one of the many civil society groups with the aim of encouraging low carbon transition (Adams and Berry, 2008). One can also envisage domestic actors influencing or even evolving into community actors such as, for example, technology owners clubs.

Going forward, the diffusion of RETs can proceed by a domestic actor pathway or community actor pathway or both. The critical questions, when exploring the impact of RETs on the attainment of policy objectives, are i) which pathway best achieves a high rate of adoption, ii) which best delivers on the five policy targets and iii) what are the best indicators by which to benchmark the attainment of policy objectives. A supplementary question may be, is there an optimal combined pathway, given the interaction between the two?

By way of explication, Table 4 shows a proposed framework to aid the development of a methodology to evaluate the impacts of the deployment of small scale renewables by domestic and community actors. A rationale for this framework is discussed below.

Table 4 Framework for evaluating the impact of community energy initiatives

\begin{tabular}{|c|c|c|c|}
\hline $\begin{array}{l}\text { Policy } \\
\text { Objective }\end{array}$ & Domestic Pathway & $\begin{array}{l}\text { Combined } \\
\text { Pathway }\end{array}$ & Community Pathway \\
\hline 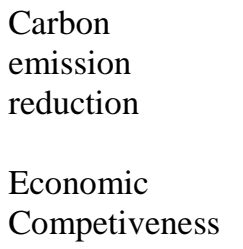 & $\begin{array}{l}\text { Diffusion rate determined } \\
\text { by number of domestic } \\
\text { adopters overcoming } \\
\text { financial and non-financial } \\
\text { barriers to the individual. }\end{array}$ & $\begin{array}{l}\text { Diffusion rate determined } \\
\text { by interaction between } \\
\text { domestic and community } \\
\text { initiatives. }\end{array}$ & $\begin{array}{l}\text { Diffusion rate determined } \\
\text { by actor agency ('power to } \\
\text { act') and influence as well } \\
\text { as financial barriers to the } \\
\text { community. }\end{array}$ \\
\hline $\begin{array}{l}\text { Energy } \\
\text { conservation } \\
\text { Social equity } \\
\text { Energy security }\end{array}$ & $\begin{array}{l}\text { Impacts on policy } \\
\text { objectives are by a more } \\
\text { individualistic domestic } \\
\text { consumer. }\end{array}$ & $\begin{array}{lrr}\text { Impacts on } & \text { policy } \\
\text { objectives are by } & \text { a } \\
\text { combination } & & \text { of } \\
\text { individualistic } & & \text { and } \\
\text { mutualistic } & \text { consumers. }\end{array}$ & $\begin{array}{l}\text { Impacts on policy } \\
\text { objectives are by a more } \\
\text { mutualistic or civil society } \\
\text { orientated community } \\
\text { consumers. }\end{array}$ \\
\hline
\end{tabular}

\section{Domestic Pathway}

Using Rogers model (Rogers, 1995) the rate of diffusion will be determined by the efficacy of the sectoral system of innovation for RETs at creating domestic adopters. Two determinants are consumer confidence, largely maintained by the effectiveness of regulatory frameworks in preventing poor installations, and the preparedness of the sector to reach beyond innovators and early adopters to those who are more technophobic and risk averse.

A key factor in attaining carbon reduction is the performance distribution function with regard to a sociotechnical system arising from a spectrum of interacting behavioural and technical performance distributions. In one study of installed PV systems, only $8 \%$ showed large energy savings after installation (Keirstead, 2007). Post-adoption effects arising from behaviour and attitudes may reduce savings due to factors such as the rebound effect (Bergman and Eyre, 2011).

The economic impacts of increasing adoption of RETS may be adverse (worsening balance of trade, higher fuel bills for non-adopters) or beneficial (employment and business opportunities). The return on investment can also be very sensitive to energy usage profiles (Wood and Rowley, 2011). Social equity, exemplified by the effects of RETs on fuel poverty are also impacted by behavioural and performance profiles. FiTs is more economically beneficial if electricity is used in-house than if exported since the export tariff is set much 
lower than the cost of grid electricity. Therefore a higher day-time electricity usage may influence whether a particular user benefits enough from a PV installation to be lifted out of fuel poverty.

Due diligence activities (Wilson et al., 2011), and an investigation in to the probabilistic distribution of performance, economic and behavioural parameters (Walters and Walsh, 2011) for RETS is required if the risk associated with the realisation of financial and carbon mitigation benefits is to be quantified.

Security of supply is the most difficult to quantify. In terms of social models, the domestic pathway is the most individualistic and may have a negative long-term impact on the predisposition of individuals to adopt more sustainable behaviours and mutualistic social structures which increase community resilience and therefore make communities less susceptible to energy security.

\section{Community Pathway}

The sectoral system of innovation has a similar task in creating community adopters as with domestic consumers. Actor agency and power to influence are key determinants of the rate of diffusion since a single community actor may result in numerous implementations of RETs. The community pathway may overcome adopter reluctance and provide a lower-effort pathway to adoption or participation by the beneficiaries of the community initiative. As evidenced by the FiTs dataset analysed here, it is hypothesised that civil society actors can create beneficiary adopters from a wider spectrum of income groups. If financial benefits are realised this increases income equality which, it has been argued, can have a positive net effect on the wellbeing of the nation (Wilkinson \& Pickett, 2010).

A key concept in the Community pathway is the idea of the niche in the multi-level perspective (MLP) model of innovation theory, the use of which here follows the 'Thousand Flowers Blooming' transition pathway (Foxon et al., 2010). According to Foxon et al, this "envisions a greater focus on more local, bottom-up diversity of solutions ... . driven by innovative local authorities and citizens groups, such as the Transition Towns movement". From our data analysis and initial case study work this pathway is exemplified by the Kirklees LSOA cluster identified in Table 3, Cornwall in Table 2 and the 49 community wind projects. Of the latter, we have identified a third sector led village wind turbine project which has just paid is first dividend of $5 \%$ to (mainly) local investors and plans to allocate a further portion of the profits to village projects.

Geels (2002) articulated the niche as the lowest level in the 3-level Multi-Level Perspective (MLP), where the seeds of socio-technical change are sown. The higher levels are the existing socio-technical regime, which represents the extant system, and the landscape which is the top-level system represented by cultural values and, for example, the global economic system. In the model, this level is only subject to very slow change indeed. MLP transition theory predicts that clusters of socio-technical niches can coalesce and interact with the regime to create a new socio-technical regime (Smith, 2003). However the community pathway faces significant challenges to overcome, particularly in developing networks of niche actors which can push for reforms of the existing regime (Hielscher et al., 2011). The data analysed here shows evidence of such networking in the Yorkshire region, Table 2.

Seyfang and Smith (2007) propose a new research and policy agenda for the study of grassroots innovations which, 'differ from the mainstream and practise quite a different sustainable development'. A bridge between policy strands promoting 'ecological modernisation and technological innovation' and 'community action and social economy' is advocated which will offer an original theoretical approach to the analysis of community-level action for sustainability. These two strands are apparent in the identification in this work of the domestic and community pathways.

Bergman and Eyre (2011) argue that the challenge to the existing regime has high stakes, and the existing landscape will not readily hand over power to decentralised grassroots innovators without a struggle. Hargreaves et al argue that MLP offers a too narrow perspective and does not account for community initiatives which cut across existing regimes and systems (Hargreaves et al., 2011). This concurs with the 
notion here of a combinatorial impact assessment of domestic and community pathways. An example of this is Energise Barnet, which is a community group driving the domestic pathway by the provision of information, advice, community capacity building, and bulk purchasing price reduction schemes.

\section{Conclusions and Further Work}

An initial analysis of the FiTs register using the theoretical lenses of innovation diffusion and transition theory has given insights into the distribution of microgeneration in England and the UK. Domestic and community consumer types are not identified within the FiTs register data, but can be categorised and grouped using geographical and socio-economic data.

It has been shown that PV is following a diffusion pattern leading to a highly dispersed geographic distribution of installations. This indicates a response to market signals, mainly by domestic consumers in more affluent neighbourhoods. Those in more deprived areas appear to be not benefitting to the same degree, though there are several noteworthy apparent community initiatives targeting low income areas, such as Kirklees and Stoke-on-Trent. Wind has a significant number of both domestic and community adopters and these appear to be mainly in rural areas of medium affluence.

There is a large body of literature focussed on the scenario approach to mapping the transition pathways to a low carbon society (Beddington et al., 2010; Skea et al., 2011). Some of these utilise quite creative scenarios with radically changed political power structures. In the analysis of the FiTs data here, the domestic and community pathways within the extant political structure are discerned. Using the method outlined here, purposeful sampling of community energy initiatives can be achieved in order to produce a wide variety of case studies. Any meaningful evaluation will need to measure the impact on policy objectives by both domestic and community pathways. This will allow a more realistic scenario approach based on the relative rates of adoption by domestic and community pathways and the synergy between them.

In ongoing work, a number of indicators or benchmarks for each policy objective will be defined and quantified. Surrogate models for sample sub-systems of the socio-technical system of systems will also be developed to help better understand the impacts of distributed RETs.

\section{References}

Adams, S., Berry, S., 2008. Low Carbon Communities A study of community energy projects in the UK.

Beddington, J., Thomas, S., Rydin, Y., 2010. Briefing: Energy and the built environment. Proceedings of the ICE - Urban Design and Planning 163, 95-99.

Bergman, N., Eyre, N., 2011. What role for microgeneration in a shift to a low carbon domestic energy sector in the UK? Energy Efficiency.

Bibby, P., Shepherd, J., 2004. Developing a New Classification of Urban and Rural Areas for Policy Purposes - the Methodology.

Boardman, B., 2010. Fixing fuel poverty: challenges and solutions. Earthscan.

Department of Energy and Climate Change, 2010. Impact Assessment of Feed-in Tariffs for Small-Scale, Low Carbon, Electricity Generation. London.

Department of Energy and Climate Change, 2011a. UK Renewable Energy Roadmap. London.

Department of Energy and Climate Change, 2011b. Digest of United Kingdom Energy Statistics 2011, Statistics. London.

Department of Energy and Climate Change, 2011c. Microgeneration Strategy. London.

Department of Energy and Climate Change, 2011d. Annual report on fuel poverty statistics.

Department of Energy and Climate Change, 2011e. Feed-in Tariffs Scheme: summary of responses to the fast-track consultation and Government response.

Dobson, A., 2010. Environmental citizenship and pro-environmental behaviour Rapid research and evidence review.

EU, 2009. Directive 2009/28/EC of the European Paliament on the promotion of the use of energy from renewable sources.

Element Energy Limited, 2008. Numbers of microgeneration units installed in England, Wales, Scotland, and Northern Ireland. 
Foxon, T.J., Hammond, G.P., Pearson, P.J.G., 2010. Developing transition pathways for a low carbon electricity system in the UK. Technological Forecasting and Social Change 77, 1203-1213.

Geels, F.W., 2002. Technological transitions as evolutionary reconfiguration processes: a multi-level perspective and a case-study. Research Policy 31, 1257-1274.

Hargreaves, T., Haxeltine, A., Longhurst, N., Seyfang, G., 2011. Sustainability transitions from the bottomup: Civil society, the multi-level perspective and practice theory.

Heath, M.A., Walshe, J.D., Watson, S.J., 2007. Estimating the Potential Yield Wind Turbines 271-287.

Helm, D., 2002. Energy policy: security of supply, sustainability and competition. Energy Policy 30, 173184.

Hielscher, S., Seyfang, G., Smith, A., 2011. Community Innovation for Sustainable Energy.

Keirstead, J., 2007. Behavioural responses to photovoltaic systems in the UK domestic sector. Energy Policy $35,4128-4141$.

Lipp, J., 2007. Lessons for effective renewable electricity policy from Denmark, Germany and the United Kingdom. Energy Policy 35, 5481-5495.

Malerba, F., 2004. Sectoral systems of innovation: concepts, issues and analyses of six major sectors in Europe. Cambridge University Press.

Marmot Review Team, 2011. The Health Impacts of Cold Homes and Fuel Poverty.

Martin, D., Nolan, A., Tranmer, M., 2001. The application of zone-design methodology in the 2001 UK Census. Environment and Planning A 33, 1949-1962.

Mendonça, M., 2007. Feed-in tariffs: accelerating the deployment of renewable energy. Earthscan.

Mitchell, C., Bauknecht, D., Connor, P., 2006. Effectiveness through risk reduction: a comparison of the renewable obligation in England and Wales and the feed-in system in Germany. Energy Policy 34, 297-305.

Mitchell, C., Connor, P., 2004. Renewable energy policy in the UK 1990 - 2003. Energy Policy 32, 19351947.

Musall, F.D., Kuik, O., 2011. Local acceptance of renewable energy - A case study from southeast Germany. Energy Policy 1-9.

Rogers, E.M., 1995. Diffusion of innovations. Free Press.

Seyfang, G., Smith, A., 2007. Grassroots innovations for sustainable development: Towards a new research and policy agenda. Environmental Politics 16, 584-603.

Skea, J., Ekins, P., Winskel, M., 2011. Energy 2050: Making the Transition to a Secure Low-Carbon Energy System. Earthscan.

Smith, A., 2003. New research agendas. Science and Public Policy 30, 127-135.

UK, 2008. Climate Change Act 2008: Chapter 27.

Unruh, G., 2002. Escaping carbon lock-in. Energy Policy 30, 317-325.

Walker, G., 2008. Decentralised systems and fuel poverty: Are there any links or risks? Energy Policy 36, 4514-4517.

Walker, G., Devine-Wright, P., 2008. Community renewable energy: What should it mean? Energy Policy 36, 497-500.

Walters, R., Walsh, P.R., 2011. Examining the financial performance of micro-generation wind projects and the subsidy effect of feed-in tariffs for urban locations in the United Kingdom. Energy Policy In Press.

Wilkinson, R., Pickett, K., 2010. The Spirit Level: Why More Equal Societies Almost Always Do Better. Penguin Books, Limited.

Wilson, D.M., Rowley, P.N., Watson, S.J., 2011. Utilizing a Risk-Based Systems Approach in the Due Diligence Process for Renewable Energy Generation. Reliability Engineering 5, 223-232.

Wood, S.R., Rowley, P.N., 2011. A techno-economic analysis of small-scale, biomass-fuelled combined heat and power for community housing. Biomass and Bioenergy 1-10.

\section{Acknowledgements}

This work is an output of a PhD research studentship funded by a Loughborough University Development Trust Centenary Award and the schools of Civil and Building Engineering and Electronic, Electrical and Systems Engineering, Loughborough University, UK. Thanks are extended to Dr Kathryn Jones of the Business School, De Montfort University, UK, for proof reading and critical comments. 